\title{
Annealing of cold-worked equiatomic Ti-Ni alloy followed by DSC and TEP methods
}

\author{
F. Khelfaoui and G. Guénin
}

\author{
GEMPPM, bâtiment 502, UMR 5510 du CNRS, INSA de Lyon, 20 avenue Albert Einstein, \\ 69621 Villeurbanne, France
}

\begin{abstract}
Systematic studies have been carried out in an equiatomic Ti-Ni shape memory alloy deformed $40 \%$ at room temperature (martensitic state) by cold working. The deformed alloy was submitted to four different annealing temperatures $\left(385^{\circ} \mathrm{C}, 425^{\circ} \mathrm{C}, 465^{\circ} \mathrm{C}\right.$ and $505^{\circ} \mathrm{C}$ ) for accumulated times. The evolution of martensitic transformation was evaluated by DSC (Differential Scanning Calorimetry). The corresponding TEP (Thermoelectric Power) was measured in the martensitic state around room temperature.

Both, the temperature and the time of annealing, are important parameters which affect the martensitic transformation. On the DSC curves, after short annealing times two peaks appear during cooling, which correspond to the $\mathbf{R}$ phase and the martensitic phase transformations. The temperature of the martensitic transformation increases with annealing time. On the other hand, the $\mathrm{R}$ phase transformation temperature is practically unchanged for all annealing times. The TEP measured in the martensitic state exhibits a clear evolution during the annealing. It has been shown that there is some relationship between TEP measurements and temperature of the martensitic transformation DSC peak, during the annealing treatments after $40 \%$ coldwork.
\end{abstract}

\section{INTRODUCTION}

It is well known, that the equiatomic Ti-Ni shape memory alloy can exhibit a third transitory phase, during Austenite $\leftrightarrow$ Martensite transformation. This phase is called $\mathbf{R}$ phase. It can occur under some conditions of thermomecanical treatment: after thermal cycling [1-4], after cold-work follown by annealing treatment [5-9], or after a phenomenon of precipitation in Ni rich Ti-Ni alloys [10-12]. Therefore, the sequence of the transformation is $A \rightarrow R \rightarrow M$ on cooling and $M \rightarrow R \rightarrow A$, or $M \rightarrow$ A on heating.

In order to characterize the sequence of martensitic transformation, DSC (Differential Scanning Calorimetry) is often used. The measure of TEP (Thermoelectric Power) has been widely used to study the precipitation phenomena in copper based alloys $[13,14]$ or aluminium ones $[15,16]$, and a bit used for restoration and recristallization measurements, for example on zircaloy alloys [17-19].

The cold-work process followed by annealing treatment produces a structural evolution of restoration and recrystallization. This, appreciably modifies the characteristics, of the martensitic transformation as well as TEP [20].

The aim of this study is to follow the structural evolution by TEP and its consequences on the martensitic transformation measured by DSC.

\section{EXPERIMENTAL PROCEDURE}

An equiatomic Ti-Ni alloy is used for this study. Plates $66 \times 4 \times 1 \mathrm{~mm}^{3}$ are annealed $2 \mathrm{~h}$ at $870^{\circ} \mathrm{C}$. They are cold worked $40 \%$ at room temperature in the martensitic state. Small DSC sample is 
carefully cut from this plate with a low speed diamond saw (weight $15 \mathrm{mg}$ ). The remaining plate is used for TEP measurement. Both samples are annealed at four different temperatures $385^{\circ} \mathrm{C}, 425^{\circ} \mathrm{C}$, $465^{\circ} \mathrm{C}$ and $505^{\circ} \mathrm{C}$ during accumulated times, follown by cooling in water. After that, samples are slightly polished to remove the oxide layer formed.

The DSC measurements are performed using Mettler TA 3000 between $-70^{\circ} \mathrm{C}$ and $120^{\circ} \mathrm{C}$ with heating and cooling rate of $5^{\circ} \mathrm{C} / \mathrm{min}$. The TEP measurements are carried out at room temperature after first cooling of the sample to liquid nitrogen temperature, this insures in all the cases the sample to be completely martensitic. The TEP measurements apparatus made in our laboratory and has been described elsewhere $[21,22]$.

\section{RESULTS}

\subsection{DSC Measurements and Behaviour of the Martensitic Transformation}

Typical DSC curves during annealing after $40 \%$ cold-work are shown on figures 1 .

Just after cold-work, no clear transformation is observed in the explored temperature range. During the annealing, the transformations gradually appear :

On cooling, the $\mathrm{R}$ peak appears first, its temperature is practically insensitive for all annealing times. While the $M$ peak is broad and becomes sharper with increasing annealing time.

On heating, a single relatively broad peak is due to the $M \rightarrow$ A transformation, it becomes sharper with annealing time increase. In this case, the peak temperature shows a little evolution.

The sequence of martensitic transformation is $A \rightarrow R \rightarrow M$ on cooling and $M \rightarrow A$ on heating. For $505^{\circ} \mathrm{C}$ heat treat temperature, the $R$ phase peak disappears after $4 \mathrm{~h}$. This elimination is delayed in the case of $465^{\circ} \mathrm{C}(37 \mathrm{~h})$ and $425^{\circ} \mathrm{C}$ (123days) heat treatments. In these cases the martensitic transformation is $\mathrm{A} \leftrightarrow \mathrm{M}$.

These results show that it is possible to define two or three regions of evolution of the martensitic transformation as a function of the annealing time. The following table shows these regions.

\begin{tabular}{|c|l|l|}
\hline Temperature of treatment & \multicolumn{1}{|c|}{ Region } & Evolution of M peak \\
\hline $385^{\circ} \mathrm{C}$ & I $: 10 \mathrm{sec} \leq \mathrm{t}_{\text {annealing }} \leq 10 \mathrm{~min}$ & $\begin{array}{l}\text { M peak badly defined } \\
\text { Evolution of M peak }\end{array}$ \\
\hline \multirow{3}{*}{$425^{\circ} \mathrm{C}$} & $\mathrm{t}_{\text {annealing }} \geq 30 \mathrm{~min}$ & $\mathrm{I}: 10 \mathrm{sec} \leq \mathrm{t}_{\text {annealing }} \leq 1 \mathrm{~min}$ \\
& $\begin{array}{l}\text { II }: 80 \mathrm{~min} \leq \mathrm{t}_{\text {annealing }} \leq 123 \text { days } \\
\text { III }: \mathrm{t}_{\text {annealing }} \geq 123 \text { days }\end{array}$ & $\begin{array}{l}\text { M peak badly defined } \\
\text { Evolution of M peak } \\
\text { Elimination of R phase }\end{array}$ \\
\hline \multirow{3}{*}{$465^{\circ} \mathrm{C}$} & I $: 10 \mathrm{sec} \leq \mathrm{t}_{\text {annealing }} \leq 30 \mathrm{sec}$ & M peak badly defined \\
& II $: 1$ min $\leq \mathrm{t}_{\text {annealing }} \leq 12 \mathrm{~h}$ & Evolution of M peak \\
& III $: t_{\text {annealing }} \geq 37 \mathrm{~h}$ & Elimination of R phase \\
\hline \multirow{2}{*}{$505^{\circ} \mathrm{C}$} & II $: 10 \mathrm{sec} \leq \mathrm{t}_{\text {annealing }} \leq 80 \mathrm{~min}$ & Evolution of M peak \\
& III $: t_{\text {annealing }} \geq 4 \mathrm{~h}$ & Elimination of R phase \\
\hline
\end{tabular}

According to this table and the figure 1 , for the four annealing temperatures a very similar evolution can be observed with different time scales. 

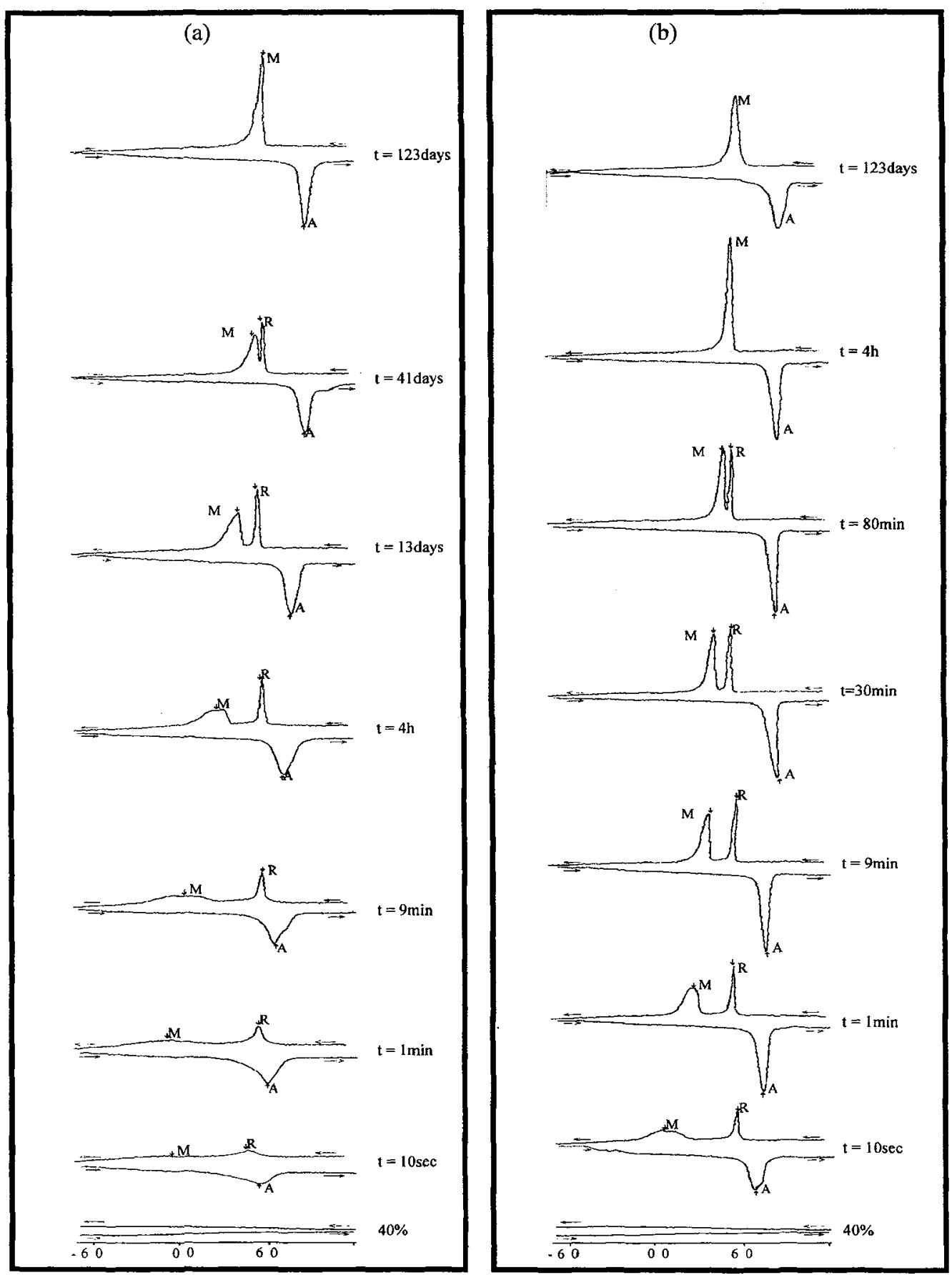

Figure 1 : Evolution of some typical DSC thermogram after $40 \%$ cold-work and heat treatment. (a) at $425^{\circ} \mathrm{C}$ and (b) at $505^{\circ} \mathrm{C}$. 
The characteristic that seems to change the most, is the $R \rightarrow M$ transformation peak temperature, which is represented on the figure 2 for the four annealing temperatures. Initially the $M$ peak is rather broad and do not change in temperature (this is only seen for $385^{\circ} \mathrm{C}$ and $425^{\circ} \mathrm{C}$ ), then a fast increase is seen followed by a saturation which seems to correspond to the $R$ transformation peak elimination

It is easily seen that, for a given peak temperature, the appearances of the thermograms are very comparable for the four annealing temperatures : compare for example $1 \mathrm{~min}$ at $505^{\circ} \mathrm{C}$ and $4 \mathrm{~h}$ at $\left.425^{\circ} \mathrm{C}\right)$

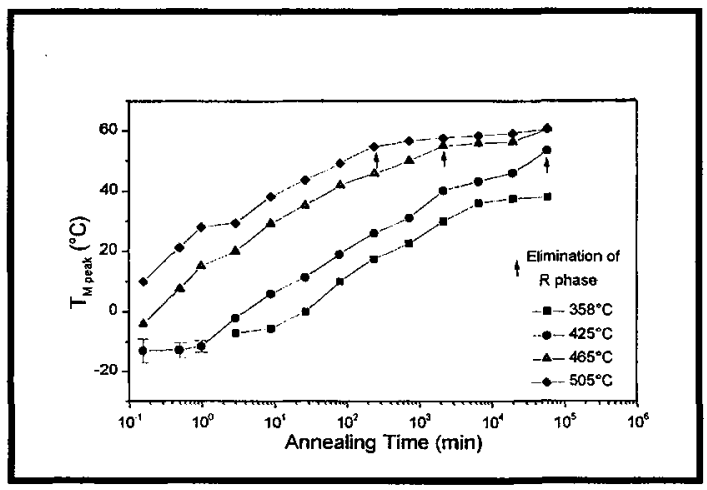

Figure 2: Evolution of $M$ Peak temperature vs annealing time.

\subsection{Thermoelectric Power (TEP) Measurements}

The evolution of TEP is represented on the figure 3 as a function of the annealing time for the four annealing temperatures. According to this figure it is seen that, for low temperature annealing a fast increase of TEP is first observed, then a linear evolution occurs which is similar for all the annealing temperatures.

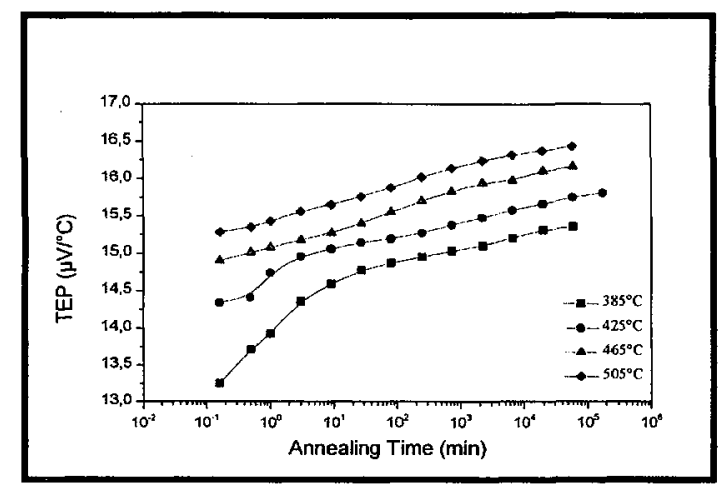

Figure 3: Evolution of TEP vs annealing time. 
The relationship between TEP and M peak temperature is illustrated on the figure 4 .

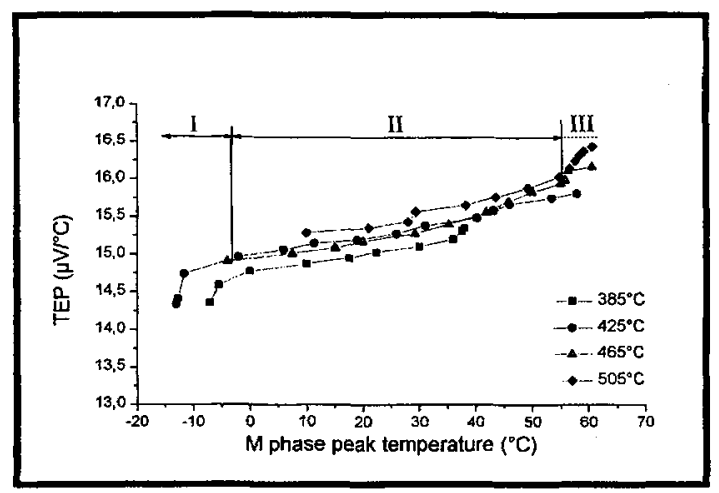

Figure 4. Evolution of TEP vs M phase peak temperature.

Three regions can be seen :

* In the region $\mathrm{I}, \mathrm{R} \rightarrow \mathrm{M}$ transformation peak temperature is relatively stable whereas the TEP changes fastly.

* In the region II, a quasi-unique linear dependence of the $\mathrm{R} \rightarrow \mathrm{M}$ transformation peak temperature with the TEP is observed.

* The region III corresponds to the saturation effect of the $\mathrm{M}$ peak temperature.

\section{DISCUSSION}

The severe cold work introduces a large amount of defects (essentially dislocation) which completely inhibits the martensitic transformation measured by DSC. The annealing treatments, through restoration and recristallization are able to regenerate the martensitic transformation. It is seen, as already shown in literature, that this occurs some evolution, in particular the emergence of two steps transformation on cooling $\mathrm{A} \rightarrow \mathrm{R} \rightarrow \mathrm{M}$ [6-9].

This study confirms that the martensitic transformation peak temperature is deeply depressed by the presence of defects whereas the $M \rightarrow$ A peak temperature is practically unaffected.

Moreover this study shows that the $\mathrm{R} \rightarrow \mathrm{M}$ transformation peak temperature progressively increases with annealing time at a given annealing temperature. The time scale of this increase is changed with the annealing temperature.

During the annealing treatments the $A \rightarrow R$ transformation peak temperature is not affected. It seems that the disappearance of this peak is associated with the temperature increase of $R \rightarrow M$ transformation which is this superimposed to the $A \rightarrow R$ one.

The figure 1 suggests that some temperature - time equivalence can be established between the heat treatments. This is confirmed by the figure 2. Moreover, the TEP which can characterize, independently, the microstructure state gives an evolution which, in a given temperature - time domain is closely correlated to the transformation evolution as shown on figure 4 (region II). It has been shown elsewhere [23] that this zone (linear evolution of TEP measurements) is associated with 
the recristallization with increasing grain size. The fast evolution of the TEP before this zone corresponds to the restoration which therefore seems to have little influence on the martensitic transformation whereas the $A \rightarrow R$ transformation clearly appears in this region.

\section{CONCLUSIONS}

$\checkmark$ It seems that the $\mathrm{R}$ phase transformation appears because it is unmasked by the decrease of martensitic transformation temperature produced by the cold-work and partially restored by annealing. The annealing leads to the temperature increase of the martensitic transformation which for a given temperature - time couple hide again the $\mathrm{R}$ phase transformation

$\checkmark$ In a given domain of annealing temperature and time some temperature - time equivalence for the transformation characteristics has been proved. This is also shown by a quasi-unique linear relationship between $T_{M \text { peak }}$ and the TEP which characterize the microstructural state of the alloy.

\section{REFERENCES}

[1] S. Miyazaki, Y. Igo and K. Otsuka, Acta. Metall. 34 (1986) 2045.

[2] G. Airoldi, B. Rivolta and C. Turco, Proc. ICOMAT 86, pp.691-696.

[3] H. Matsumoto, J. Mater. Sci. Lett., 10 (1991) 408.

[4]] S. Chouf, F. Khelfaoui, S. Belkahla, M. Morin, G. Guénin, Mater Sci and Eng, to be published 2000

[5] D. N. Abujudom, P. E Thoma and S. Fariabi, Mater. Sci. For., 56-58 (1990), 565.

[6] H. C. Lin and S. K. Wu, Metall. Trans 24 A (1993), 293.

[7] P. E Thoma, M-Y. Kao, S. Fariabi and D. N. Abujudom, Proc. ICOMAT 92, 917.

[8] S. K. Wu, H. C. Lin and Y. C. Yen, Mater. Sci. and Eng., A215, (1996) 113.

[9] P. E. Thoma, D. R. Angst and K. D. Schachner, J. Phys IV, Colloque C8, Spplément au Journal de Physique III, Vol.5, C8-557 - C8-563, 1995.

[10] H. C. Lin, S. K. Wu, Scripta Met. 25 (1991), 1295.

[11] Q. Chen, X. F. Wu, T. KO, Scripta Met., 29 (1993), 49.

[12] A. Ishida, M. Sato, A. Takei, K. Nomura, S. Miyazaki, Metall. Trans 17 A (1996) 3753

[13] J. M. Pelletier, R. Borrelly and E. Prenoux, Physica. Status. Solidi. (a), 39 (1977), 525.

[14] R. Borrelly, J. M. Pelletier and P. F. Gobin, Acta. Metall., 26 (1978), 1863.

[15] J. M. Pelletier, J. Merlin and R. Borrelly, Mater. Sci. and Eng., 33 (1978), 95.

[16] P. Merle, J. M. Pelletier and J. Merlin, Mém. Sci. Revue Métall., 3 (1979), 209.

[17] P. Merle, C. Vauglin, G. Fantozzi, J. L. Derep and D. Charquet, American Society for Testing and Materials,(1987), 555.

[18] D. O. Northwood, J. W. Robinson and J. Zheng, J. Mater. Eng. and Perf, 1 (1992), 143.

[19] Z. Farhat and D. O. Northwood, Mater. Sci. For., 113-115 (1993), 649.

[20]. C. M. Jackson, H. J. Wagner and R. J. Wasilewski, 55-Nitinol- The Alloy with a Memory : Its Physical Metallurgy, Properties and Applications. Report n ${ }^{\circ}$ NASA-SP 5110, 1972, 83p.

[21]. R. Borrelly, Mém Sci Revue Métall, (1979), 37.

[22] R. Borrelly and D. Benkirat, Acta. Metall., 33 (1985), 855.

[23] F. Khelfaoui, G. Thollet and G. Guénin, to be published. 